\title{
Racial differences in lung cancer
}

\author{
Shirish M. Gadgeel ${ }^{1}$ and Gregory P. Kalemkerian ${ }^{2 *}$ \\ ${ }^{1}$ Department of Medicine, Wayne State University, Karmanos Cancer Institute, Detroit, MI; ${ }^{2}$ Department of \\ Medicine, University of Michigan, Ann Arbor, MI
}

Key words: lung cancer, race, African American, epidemiology, incidence, survival

\section{Summary}

Although race, in and of itself, is not a relevant biologic variable, racial differences in disease characteristics and outcomes have been reported in many malignancies, including lung cancer. The lung cancer incidence rate in blacks has been consistently higher than that in whites for many years. This racial disparity is seen primarily in men and is significantly greater in younger age groups. The reason for higher lung cancer incidence rates in blacks remains unclear, but racial differences in smoking habits, socioeconomic variables, and the metabolism of tobacco carcinogens may all play an important role. Blacks are also more likely than whites to present with squamous cell carcinoma and with advanced-stage disease. A significant racial difference in survival rates has developed over the past 30 years, with a poorer prognosis noted in black patients, particularly those with local- and regional-stage disease. This disparity appears to be due to a lack of improvement in the survival of black patients with lung cancer, but the biological and/or societal basis for racial variations in survival have not been determined. In summary, significant racial differences exist in lung cancer incidence and survival rates. Further research is required to determine the factors responsible for these differences and to develop effective preventative and therapeutic interventions that will impact favorably on the incidence and prognosis of this disease.

\section{Introduction}

Lung cancer is currently the most common cause of cancer-related mortality for both men and women in the US, and is likely to remain so despite recent declines in lung cancer mortality rates [1]. During the last century, lung cancer evolved from a rare pathologic entity to a major public health problem due to the dramatic increase in the prevalence of cigarette smoking. On the positive side, the strong association between tobacco use and lung cancer provides the opportunity for relatively straight-forward public health measures to have a major longterm impact on the incidence of this disease. In addition, the magnitude of the problem will allow for small improvements in the treatment of lung cancer to translate into major public health benefits.

For many years, race was considered an important biologic factor that could affect both the development and outcome of many diseases. However, advances in genetics and the social sciences have demonstrated that race, in and of itself, is usually not a relevant biologic variable [2]. It is now clear that race is an imperfect and complex variable with strong socioeconomic associations and questionable biological significance. Nonetheless, the analysis of racial differences in a diseased cohort can identify important clinicopathologic variations that may lead to useful interventions aimed at the specific needs of a

\footnotetext{
* Corresponding author.

E-mail: kalemker@umich.edu
} 
targeted sub-population [3]. Racial differences in disease characteristics and outcomes are well recognized for many malignancies, including lung cancer [4-6]. In recent years, the recognition of higher incidence rates and lower survival rates for lung cancer in blacks compared to whites has received increasing public attention [7]. These racial differences have been attributed to a variety of factors, including smoking habits, socioeconomic status, genetic susceptibility, occupational exposure, diet, and treatment.

In order to further characterize racial variations in the clinicopathologic features of lung cancer, we previously reported an analysis of data collected by the metropolitan Detroit Surveillance, Epidemiology and End Results (SEER) registry from 1973-1998 [8]. Of the 48,318 patients with primary lung cancer included in our report, $23 \%$ were black, $34 \%$ were female, and $8 \%$ were under 50 years of age at diagnosis. This review will consider the racial disparities in incidence, histology, stage, and survival that have been observed in patient with lung cancer and will offer some insight into the potential reasons behind these differences.

\section{Incidence}

Over the last 40 years, lung cancer incidence rates have been consistently higher in blacks than in whites [1,9]. This difference is gender specific, with incidence rates in black men being reported as 35$50 \%$ higher than those in white men, while the incidence rates in women of both races have been similar $[8,10]$. In our analysis of the metropolitan Detroit SEER registry, the age-adjusted incidence rates (per 100,000 person-years) were 85.8 in black men, 62.7 in white men, 29.6 in black women, and 27.1 in white women (Figure 1) [8]. Since the early 1980s, lung cancer incidence rates have been decreasing in men of both races, but this decline has been greater in black men [8]. Unfortunately, incidence rates in women of both races have continued to rise, though recent data suggests that they may be reaching a plateau.

The degree of the racial differences in lung cancer incidence also varies with age, with greater disparity noted in younger population groups [8,11]. In our analysis of the metropolitan Detroit SEER registry, lung cancer incidence in younger black men (age $<50$ years) was over 2 -fold higher than in younger white men $(10.4 / 100,000$ vs. $5.1 /$ $100,000, p<0.05)$. Despite an overall decrease in the incidence of lung cancer in men of both races, the racial disparity in younger men continued to increase throughout the study period [8]. Such agerelated variations in incidence rates between blacks and whites have also been reported in other cancers, suggesting significant racially associated differences in susceptibility to various carcinogens. The higher rate of lung cancer in young black men is surprising considering that blacks generally start smoking at a later age and smoke fewer cigarettes per day. It is possible non-smoking-related factors, such as other environmental exposures or socioeconomic status, may have greater impact in younger individuals.

\section{Tobacco use}

Racial differences in smoking patterns have been extensively evaluated. Smoking prevalence rates of blacks and whites were similar up until the 1960s when significant differences began to emerge, primarily in men $[9,12]$. However, these disparities in smoking prevalence rates cannot fully explain the racial differences in lung cancer incidence rates since there was substantial temporal overlap in their emergence. In addition, the magnitude of the racial difference in smoking prevalence (1960s: black 43\%, white 40\%; 1980s: black 34\%, white $29 \%$; 1998: black $29 \%$, whites $27 \%$ ) is substantially smaller than that in lung cancer incidence $[12,13]$.

In addition to the differences in prevalence, smoking patterns and habits have also been shown to vary along racial lines. Black smokers tend to start smoking at a later age and smoke fewer cigarettes per day, but are less likely to quit $[12,14]$. In 1987, the quit rate was $32 \%$ for black smokers and $47 \%$ for whites [12]. Thus, blacks are more likely to be long-term smokers, potentially increasing their risk of developing tobacco-related disorders, such as lung cancer. Since smoking initiation rates are similar in blacks and whites, it has been proposed that the lower quit rate in blacks is the primary reason for the racial differences noted in smoking prevalence rates.

The use of mentholated cigarettes is much more common in blacks, with 70-80\% of black smokers and only $20-30 \%$ of the white smokers regularly 


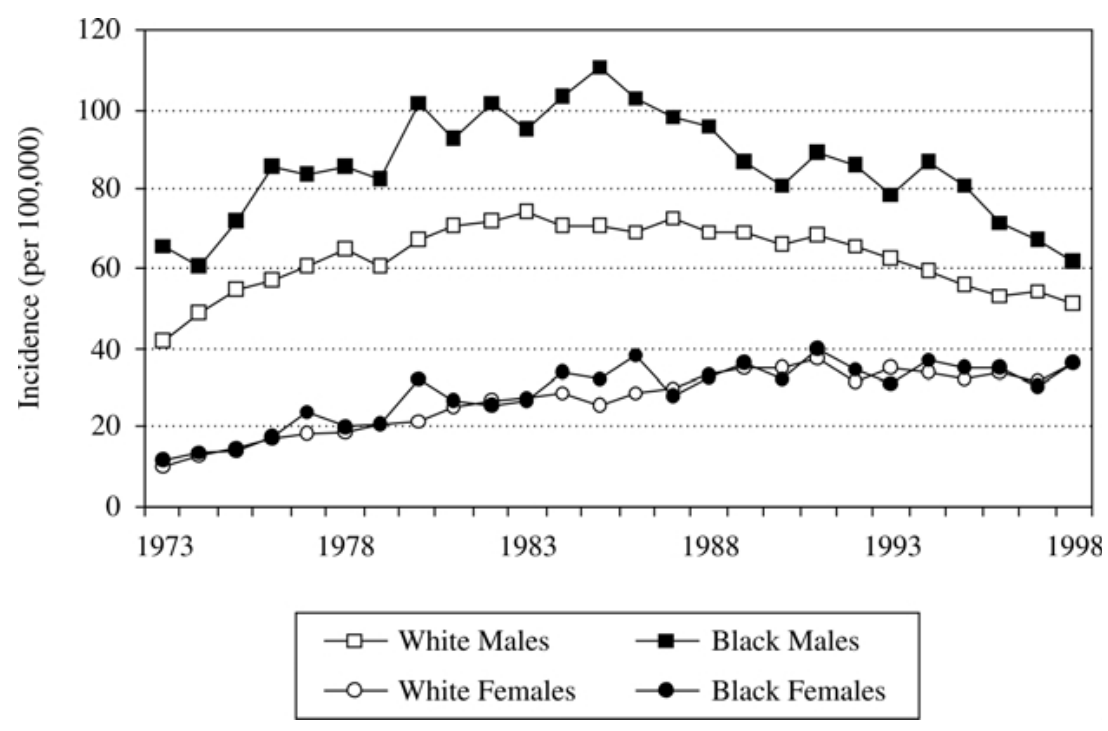

Figure 1. Age-adjusted incidence rates of lung cancer by race and gender in metropolitan Detroit (1973-1998). (Reprinted from Gadgeel et al. [8]).

smoking mentholated cigarettes [15]. It has been hypothesized that the use of mentholated cigarettes can increase the risk of lung cancer since they have higher tar content than non-mentholated cigarettes [16], generate higher levels of known carcinogens [17], facilitate the absorption of carbon monoxide [18], and limit ventilation leading to greater pulmonary retention of tobacco smoke $[19,20]$. Two studies have suggested an association between mentholated cigarette use and higher lung cancer risk in men, although the results of population-based studies remain inconclusive [21-23]. Overall, blacks also smoke cigarettes with higher tar and nicotine content, potentially enhancing dependence and the risk of lung cancer $[14,24]$.

\section{Socioeconomic factors}

The importance of socioeconomic variables as cancer risk factors and prognostic markers has been recognized by many investigators. Socioeconomic factors, such as lower income and education level, are associated with a higher risk of lung cancer and a higher overall cancer mortality rate $[25,26]$. Prior analyses of the SEER registry have found that most black cancer patients live in high population density areas with lower median incomes and education levels, and that age-adjusted lung cancer incidence rates are inversely related to family income and level of education [27-29]. In addition, the lung cancer incidence rate in blacks was slightly lower than in whites after adjustment for socioeconomic status, suggesting that these factors play an important role in determining the high lung cancer risk observed in the black community.

Socioeconomic status correlates with a variety of lifestyle factors that may impact on lung carcinogenesis, such as tobacco and alcohol use, diet, and exposure to occupational and environmental carcinogens [30]. Lower socioeconomic status is associated with higher smoking prevalence and nicotine-dependence rates, greater use of non-filter, high-tar cigarettes, and a lower quit rate $[6,12,28]$. With regard to diet, the Health and Nutrition Examination Survey reported that the diet of American blacks contains more fat and fewer fruits and vegetables, dietary factors that are known to be associated with a higher risk of lung cancer, than that of whites [31-33]. In a casecontrol study, Swanson and colleagues noted that whites ate more raw vegetables, while blacks ate more preserved and processed meat with greater carcinogenic potential [34].

Blacks also may have greater occupational and environmental carcinogen exposure and greater susceptibility for the development of lung cancer 
after such exposure than whites. A case-control study by Muscat and colleagues suggested that occupational exposure to lung carcinogens may be more common in blacks than in whites and that exposure to asbestos and coal significantly increased the risk of lung cancer in black males [35]. Swanson and colleagues evaluated the relationship between race, occupation and lung cancer risk in metropolitan Detroit, and reported that among occupations associated with an increased risk of lung cancer, the risk in black males was consistently greater than in white males [36].

\section{Genetic and metabolic pathways}

Although recent genetic studies have suggested that race does not have general biological relevance, the prevalence of a number genetic variations (polymorphisms) in genes that may affect the susceptibility to tobacco carcinogens have been found to vary significantly along racial lines. Thus far, genetic studies have primarily focused on genes encoding for enzymes that are involved in the metabolism of environmental and tobaccorelated carcinogens, such as the cytochrome P450 family members CYP1A1, involved in carcinogenic activation of hydrocarbons, CYP2C9, involved in the activation of benzo[a]pyrene, and CYP2E1, involved in the metabolic activation of tobacco-specific nitrosamines [37-40]. Many studies have reported on the occurrence of various polymorphisms of these genes in racial subgroups and their association with lung cancer incidence. These reports have frequently yielded conflicting data and are confounded by the general lack of knowledge regarding the functional consequences, if any, of the evaluated polymporphisms. In general, a consistent association between genetic polymorphisms in metabolic enzymes and the incidence of lung cancer in any racial subpopulation has not been clearly demonstrated.

However, there do appear to be reproducible racial differences in the intake and metabolism of nicotine. Perez-Stable and colleagues reported that black smokers had higher serum levels of cotinine, a metabolite of nicotine, despite similar daily cigarette consumption, and a $30 \%$ higher intake of nicotine per cigarette than white smokers [41]. These differences may be due to genetic variations in metabolic enzymes, more frequent use of mentholated cigarettes in blacks, or habitual differences in the frequency or depth of smoke inhalation. Similar results have been reported from a national study of over 7,000 smokers [42]. These findings may help to explain both the low quit rate and the high incidence of lung cancer consistently observed in blacks.

Considering all of the aforementioned data, it is likely that the cause of the observed racial differences in lung cancer incidence is multifactorial, involving a wide variety of tobaccorelated, socioeconomic, and genetic factors.

\section{Histology and stage}

Over the last 15 years, adenocarcinoma has replaced squamous cell carcinoma as the predominant histologic subtype of lung cancer in the US [4]. This histologic shift has been observed in both blacks and whites, and appears to be temporally associated with the introduction of filter-tip cigarettes with lower tar and nicotine content [43]. It is speculated that filter-tip cigarettes allow deeper inhalation of tobacco smoke, increasing the carcinogen exposure of peripheral airways in which adenocarcinoma arises. In our analysis of the metropolitan Detroit SEER registry, the incidence of squamous cell carcinoma declined more in blacks than in whites during the study period [8]. However, the overall incidence of squamous cell carcinoma remained higher in both black males and females, perhaps due to greater use of non-filtered, high-tar, high-nicotine cigarettes by blacks or the existence of more longterm black smokers [14,44].

Stage of disease at presentation is the most important prognostic factor in lung cancer. Unfortunately, most patients present with locally advanced or metastatic disease, accounting for the high overall mortality rate associated with this disease. Significant racial differences have been observed in the stage of lung cancer at presentation, with blacks exhibiting a higher incidence of advanced-stage disease than whites $[8,45,46]$. Over the past 25 years, the proportion of all patients with advanced-stage disease has increased, primarily due to improvements in the sensitivity and availability of state-of-the-art staging modalities. Over the same period of time, the racial disparity 
in stage at presentation also increased, with the proportion of patients with distant-stage disease increasing from $44 \%$ to $53 \%$ in blacks and from $42 \%$ to $48 \%$ in whites [8]. In addition, the incidence rate for potentially curable early-stage disease declined in blacks (11.6 to $9.7 / 100,000)$, but increased slightly in whites $(8.9$ to $9.2 / 100,000)$. Racial differences in health care access and attitudes may account for some of this racial disparity in stage.

\section{Therapy and survival}

The overall 5-year survival rate for patients with lung cancer has increased from $8 \%$ to $14 \%$ over the past 30 years. Numerous analyzes have demonstrated that survival rates for black patients with lung cancer are lower than for white patients [4]. In our study of the metropolitan Detroit SEER registry, we noted that the survival gap between black and white lung cancer patients has widened significantly since the mid-1980s (Figure 2) [8]. From 1973-1985, overall 5-year survival was $11.3 \%$ in blacks and $12.7 \%$ in whites $(p=0.067)$, while from $1986-1998$, it was $11.5 \%$ in blacks and $16.5 \%$ in whites $(p<0.0001)$. It appears that this gap is primarily due to modest improvements in the overall survival rates of white patients with local- and regional-stage disease, while the survival rates of black patients have remained relatively unchanged over the last 25 years. This trend has resulted in stage-specific 5-year survival rates that are significantly lower for black patients with local-stage $(37.1 \%$ vs. $45.3 \%, p=0.0001)$ and regional-stage $(14.8 \%$ vs. $23.7 \%, p<0.0001)$ disease [8].

Survival in lung cancer is influenced by multiple factors, including stage of disease, performance status, the presence of co-morbid conditions, and access to health care. Some of these factors may have particular importance in the treatment of regional-stage disease, where the greatest change in black versus white survival has occurred. Since the mid-1980s, the widespread use of combined modality therapy has led to modest improvement in the survival of patients with regional-stage lung cancer. This type of treatment is expensive and logistically complicated, and requires a good performance status, all of which may impede the availability of combined modality therapy to patients with lower socioeconomic status. Several factors, including lower socioeconomic status and increased rates of long-term smoking, can be associated with a greater probability of significant co-morbid conditions and poorer performance

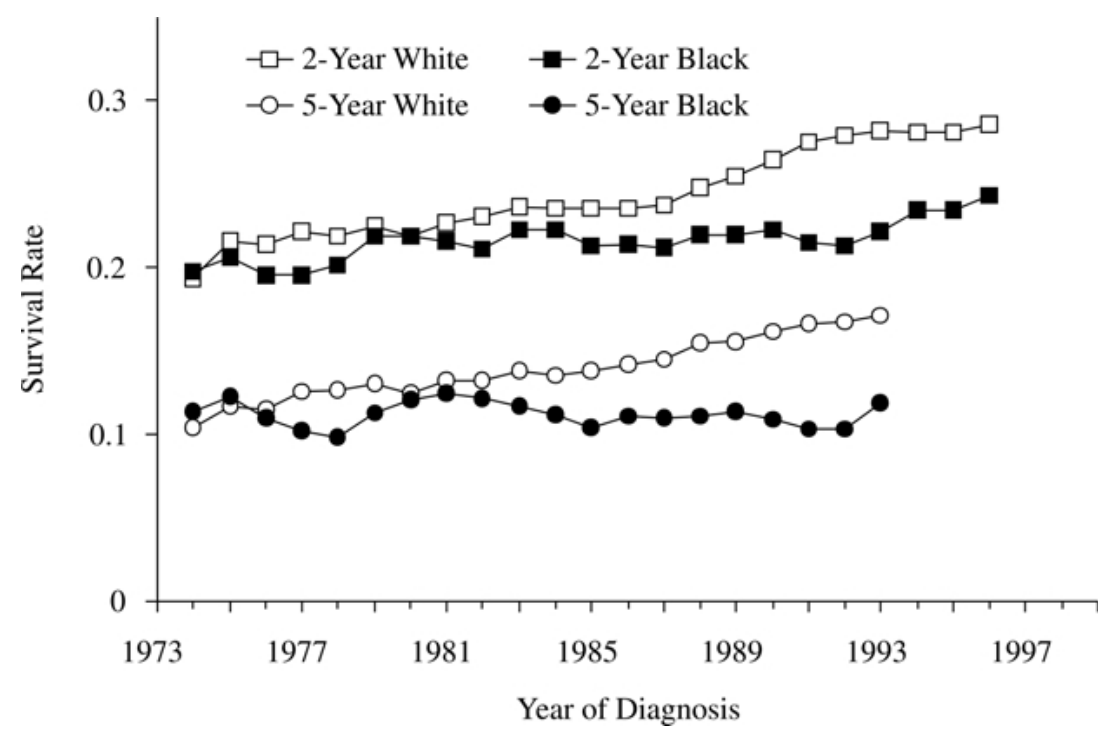

Figure 2. Relative 2- and 5-year survival rates of lung cancer patients at all stages by race in metropolitan Detroit (1973-1997, calculated by 3-year moving average). (Reprinted from Gadgeel et al. [8].) 
status in black patients with lung cancer. Due to the potential toxicity of aggressive anticancer therapy, the presence of co-morbid conditions can have a substantial impact on treatment decisions and prognosis.

Several investigators have noted that white patients undergo significantly more cancer-directed surgery than blacks [45]. A recent study reported that the 5-year survival difference between elderly black and white patients $(26.4 \%$ vs. $34.1 \%$ ) with early-stage lung cancer was associated with lower surgical resection rates in black patients (64\% vs. $77 \%$ ) despite the lack of any racial difference in co-morbidity [47]. Of particular interest, there was no difference in the survival of black and white patients who underwent surgery. Lack of personal resources and jaded personal perceptions of the health care system can limit access to appropriate health care, thereby preventing early diagnosis and appropriate treatment of many diseases, including lung cancer. In the US, a greater proportion of the black population is uninsured and many blacks exhibit profound distrust of the current health care establishment [48-50]. In a Veterans' Administration study evaluating outcomes of veterans with advanced lung or colon cancer, the survival of patients of both races was similar despite lower overall socioeconomic status in black patients, suggesting that equal access to comparable health care results in equal outcomes [51].

\section{Conclusions}

Studies on the biological impact of race must be interpreted cautiously due to the complex nature of the race variable and the exclusion of many relevant socioeconomic parameters from most disease-based databases. Overall, significant declines in the incidence and mortality of lung cancer in select subsets of the population are encouraging. However, in the last two decades several disturbing racial trends have developed, including the lower relative decline in lung cancer incidence in younger black males, the greater trend toward advanced-stage disease blacks, and the widening racial disparity in survival. These racial trends are likely due to the interaction of a variety of lifestyle, socioeconomic, and genetic factors. An appropriate understanding of these differences is an important step in the development and implementation of more effective preventive and therapeutic strategies that will have a positive impact on all patients with lung cancer.

\section{References}

1. Jemal A, Thomas A, Murray T, Thun M: Cancer statistics, 2002. CA Cancer J Clin 52: 23-47, 2002

2. Freeman HP: The meaning of race in science - considerations for cancer research: Concerns of special populations in the National Cancer Program. Cancer 18: 219-225, 1998

3. Brawley OW, Freeman HP: Race and outcomes: Is this the end of the beginning for minority health research? J Natl Cancer Inst 91: 1908-1909, 1999

4. Wingo PA, Ries LA, Giovino GA, Miller DS, Rosenberg HM, Shopland DR, Thun MJ, Edwards BK: Annual report to the nation on the status of cancer, 1973-1996, with a special section on lung cancer and tobacco smoking. J Natl Cancer Inst 91: 675-690, 1999

5. Wu LY, Semenya KA, Hardy RE, Hargreaves MK, Robinson SB, Pederson L, Sung JF, Haynes MA: Cancer rate differentials between blacks and whites in three metropolitan areas: A 10-year comparison. J Natl Med Assoc 90: 410-416, 1998

6. Cooley ME, Jennings-Dozier K: Lung cancer in AfricanAmericans - a call for action. Cancer Pract 6: 99-106, 1998

7. Stewart JH: Lung carcinoma in African Americans - a review of the current literature. Cancer 91: 2476-2482, 2001

8. Gadgeel SM, Severson RK, Kau Y, Graff J, Weiss LK, Kalemkerian GP: Impact of race in lung cancer - analysis of temporal trends from a surveillance, epidemiology, and end results database. Chest 120: 55-63, 2001

9. Blot WJ, Fraumeni JF: Changing patterns of lung cancer in the United States. Am J Epidemiol 115: 664-673, 1982

10. Howe HL, Wingo PA, Thun MJ, Ries LA, Rosenberg HM, Feigal EG, Edwards BK: Annual report to the nation on the status of cancer featuring cancers with recent increasing trends. J Natl Cancer Inst 93: 824-842, 2001

11. Satariano WA, Swanson GM: Racial differences in cancer incidence: The significance of age-specific patterns. Cancer 62: 2640-2653, 1988

12. Fiore MC: Trends in cigarette smoking in the United States. The epidemiology of tobacco use. Med Clin North Am 76: 289-303, 1992

13. Cigarette smoking among adults - United States, 1998. MMWR 49: 881-884, 2000

14. Kabat GC, Morabia A, Wynder EL: Comparison of smoking habits of blacks and whites in a case-control study. Am J Public Health 81: 1483-1486, 1991

15. Cummings KM, Giovino G, Mendicino AJ: Cigarette advertising and black-white differences in brand preference. Public Health Rep 102: 698-701, 1987 
16. Richardson TL: African-American smokers and cancers of the lung and of the upper respiratory and digestive tracts. Is menthol part of the puzzle? West J Med 166: 189-194, 1997

17. Schmeltz I, Schlotzhaur WS: Benzo(a)pyrene, phenols, and other products from pyrolysis of the cigarette additive, (dl)menthol. Nature 219: 370-371, 1968

18. Clark PI, Gautam S, Gerson LW: Effect of menthol cigarettes on biochemical markers of smoke exposure among black and white smokers. Chest 110: 1194-1198, 1996

19. McBride B, Whitelaw WA. A physiological stimulus to upper airway receptors in humans. J Appl Physiol 51: 1189-1197, 1981

20. Orani GP, Anderson JW, Sant'Ambrogio G, Sant'Ambrogio FB: Upper airway cooling and 1-menthol reduce ventilation in the guinea pig. J Appl Physiol 70: 20802086,1991

21. Carpenter CL, Jarvik ME, Morgenstern H, McCarthy WJ, London SJ: Mentholated cigarette smoking and lungcancer risk. Ann Epidemiol 9: 114-120, 1999

22. Kabat GC, Hebert JR: Use of mentholated cigarettes and lung cancer risk. Cancer Res 51: 6510-6513, 1991

23. Sidney S, Tekawa IS, Freidman GD, Sadler MC, Tashkin DP: Mentholated cigarette use and lung cancer. Arch Int Med 155: 727-732, 1995

24. McGrady GA, Ahluwalia JS, Pederson LL: Smoking initiation and cessation in African-Americans attending an inner-city walk-in clinic. Am J Prev Med 14: 130-137, 1998

25. Wynder EL, Covey LS, Mabuchi K: Current smoking habits by selected background variables: Their effect on future disease trends. Am J Epidemiol 100: 168-177, 1974

26. Jenkins CD: Social environment and cancer mortality in men. N Engl J Med 308: 395-398, 1983

27. Baquet CR, Horm JW, Gibbs T, Greenwald P: Socioeconomic factors and cancer incidence among blacks and whites. J Natl Cancer Inst 83: 551-557, 1991

28. Novotny TE, Warner KE, Kendrick JS, Remington PL: Smoking by blacks and whites: Socioeconomic and demographic differences. Am J Public Health 78: 1187-1189, 1988

29. Devesa SS, Diamond EL: Socioeconomic and racial differences in lung cancer incidence. Am J Epidemiol 118: $818-831,1983$

30. Bang KM, Perlin E, Sampson CC: Increased cancer risks in blacks - a look at the factors. J Natl Med Assoc 79: 383388, 1987

31. Mettlin C: Nutritional habits of blacks and whites. Prev Med 9: 601-606, 1980

32. LeMarchand L, Yoshizawa CN, Kolonel LN, Hankin JH, Goodman MT: Vegetable consumption and lung cancer risk: A population-based case-control study in Hawaii. J Natl Cancer Inst 81: 1158-1164, 1989

33. Dorgan JF, Ziegler RG, Schoenberg JB, Hartge P, McAdams MJ, Falk RT, Wilcox HB, Shaw GL: Race and sex differences in associations of vegetables, fruits, and carotenoids with lung cancer risk in New Jersey. Cancer Causes Control 4: 273-281, 1993
34. Swanson CA, Gridley G, Greenberg RS, Schoenberg JB, Swanson GM, Brown LM, Hayes R, Silverman D, Pottern $\mathrm{L}$ : A comparison of diets of blacks and whites in three areas of the United States. Nutr Cancer 20: 153-165, 1993

35. Muscat JE, Stellman SD, Richie JP Jr, Wynder EL: Lung cancer risk and workplace exposures in black men and women. Environ Res 76: 78-84, 1998

36. Swanson GM, Lin CS, Burns PB: Diversity in the association between occupation and lung cancer among black and white men. Cancer Epidemiol Biomarker Prev 2: 313-320, 1993

37. Taioli E, Ford J, Trachman J, Demopoulos R, Garte S: Lung cancer risk and CYP1Al genotype in AfricanAmericans. Carcinogenesis 19: 813-817, 1998

38. Wu X, Amos CI, Kemp BL, Shi H, Jiang H, Wan Y, Spitz MR: Cytochrome P450-2E1 DraI polymorphisms in lung cancer in minority populations. Cancer Epidemiol Biomarker Prev 7: 13-18, 1998

39. Kelsey KT, Wiencke JK, Spitz MR: A race-specific genetic polymorphism in the CYP1A1 gene is not associated with lung cancer in African-Americans. Carcinogenesis 15: 1121-1124, 1994

40. London SJ, Daly AK, Leathart JBS, Navidi WC, Idle JR: Lung cancer risk in relation to the CYP2C $9 * 1 / \mathrm{CYP} 2 \mathrm{C} 9 * 2$ genetic polymorphism among African-Americans and Caucasians in Los Angeles County, California. Pharmacogenetics 6: 527-533, 1996

41. Perez-Stable EJ, Herrera B, Jacob P, Benowitz NL: Nicotine metabolism and intake in black and white smokers. JAMA 280: 152-156, 1998

42. Caraballo RS, Giovino GA, Pechacek TF, Mowery PD, Richter PA, Strauss WJ, Sharp DJ, Eriksen MP, Pirkle JL, Maurer KR: Racial and ethnic differences in serum cotinine levels of cigarette smokers: Third National Health and Nutrition Examination Survey, 1988-1991. JAMA 280: 135-139, 1998

43. Wynder EL, Hoffmann D: Smoking and lung cancer: Scientific challenges and opportunities. Cancer Res 54: 5284-5295, 1994

44. Sterling TD, Weinkam JJ: Comparison of smoking-related risk factors among black and white males. Am J Ind Med 15: 319-333, 1989

45. Fry WA, Menck HR, Winchester DP: The national cancer data base report on lung cancer. Cancer 77: 1947-1955, 1996

46. Graham MV, Geitz LM, Byhardt R, Asbell S, Roach M, Urtasun RC, Curran WJ, Lattin P, Russell AH, Cox JD: Comparison of prognostic factors and survival among black patients and white patients treated with irradiation for non-small-cell lung cancer. J Natl Cancer Inst 84: 17311735, 1992

47. Bach PB, Cramer LD, Warren JL, Begg CB: Racial differences in the treatment of early-stage lung cancer. N Engl J Med 341: 1198-1205, 1999

48. EVAXX: Black American attitudes toward cancer and cancer tests: Highlights of a study. CA Cancer J Clin 31: 212-218, 1981

49. Horm JW, Devesa SS, Burhansstipanov L: Cancer inci- 
dence, mortality, and survival among racial and ethnic minority groups in the United States. In: Schottenfeld D, Fraumeni JF (eds) Cancer Epidemiology and Prevention. Oxford University, New York, 1996, pp 192-235

50. Freeman HP: Cancer in the socioeconomically disadvantaged. CA Cancer J Clin 39: 266-288, 1989
51. Akerley WL, Moritz TE, Ryan LS, Henderson WG, Zacharski LR: Racial comparison of outcomes of male Department of Veterans Affairs patients with lung and colon cancer. Arch Intern Med 153: 1681-1688, 1993 